\title{
The Future of Engineering Education in South Africa
}

\author{
Dr Kehdinga George Fomunyam \\ Mangouthu University of Technology
}

ORCID: 0000-0003-2510-3498

\begin{abstract}
Engineering is a field of practice that has ties with development, acquisition, and use of technical, scientific and mathematical knowledge to have a grasp of design, development, invention, innovation and the application of materials, machinery, structures, systems, and processes for designed purposes. South Africa is the center of engineering education in Africa as a result of adequate infrastructures that are important for the offering of engineering education as a discipline. With various changes happening in the South African higher education landscape in particular and the nation in general especially within this era of the Fourth industrial revolution, the future of engineering education in South Africa is set to change. This paper is a theoretical analysis of the various concepts which might likely defined the future of engineering education in South Africa. Evidences from established literatures were used in lending support to the major arguments of the paper. With the general economic trend in Africa, environmental challenges, and the rapid development of technologies, the future of engineering education will be influenced. This paper argues that the future of engineering education will have in it three emerging areas which are automation, additive manufacturing, and industrial internet which will influence the discipline. The paper recommends that there is a need for the government to invest heavily in building the knowledge economy, intensify efforts on STEM education which has the ability to contribute to engineering education in South Africa and there is a need to incorporate into the curriculum leadership and management courses, critical thinking, change management, communication, and crisis management.
\end{abstract}

Keywords: Engineering, engineering education, future.

\section{Introduction}

Although engineering is replete with lots of definitions, notable amongst them is the one given by Tredgold (1828) in which he sees engineering as the art of directing the enormous streams of power in nature for man's use and convenience. Following his definition, the American Society for engineering education aligns by maintaining that engineering is the art of applying scientific and mathematical principles, experiences, judgment and common sense to make things benefit people. These definitions have a major function in it which is to benefit man by making his work convenient. Engineering is a field of practice that has ties with development, acquisition, and use of technical, scientific and mathematical knowledge to have a grasp of design, development, invention, innovation and the application of materials, machinery, structures, systems, and processes for designed purposes (Martin, 2018). The discipline is a composite of others such as technology, science, and mathematics, and these other disciplines are necessary for facilitating the knowledge, design, and use of machinery for specified purposes. The field of engineering education relies on others to lend credence to it and it does not stand alone. Engineering education has with it various concept which can only be found in other disciplines such as sciences, technology, mathematics.

Zeiteh (2002) argued that most engineering programs in Africa were patterned by colonial governments and the overall engineering education system and curricula were taken from the colonial rulers. This eventually led to the incessant calls for the decolonization of higher education in general and engineering education particular in South Africa (Fomunyam, 2017). ECSA (2016) has noted that there is a shortage of engineers in South Africa and the key to changing this is engineering education. As such, engineering education must take new shape and pace to ensure that future engineers who are currently being trained meet up with the demands of the fourth industrial revolution especially because the said revolution is currently changing and shifting the entire business and educational landscape. This paper will consider engineering education holistically seeking to understand the practice as a whole, the challenges of engineering education and further theorise a future path for the discipline in South African higher education.

\section{The present situation and the challenges facing engineering education in South Africa}

It is now known globally that engineering practices are the very foundation of society and it contributes to the development of society. Taking a cue from historical perspectives, engineering education has influenced life, culture and the interaction of humans. In the early days of engineering activities, the pyramids of Egypt ( 2500BC, Egypt) King Goujians bronze sword $(\sim 500 \mathrm{BC}$, China), the Dujiangyan water engineering system $(\sim 300 \mathrm{BC}$, China) and the Great Wall of China ( 206BC, China) were some of the notable sceneries in history that lends support to the early development of engineering. What helped was the intelligence and experiences of early men while modern engineering has at its core science and technology. Engineering skills globally are recognized to be 
gotten from technical colleges, polytechnics, monotechnics, and universities and these skills are vital for technological, economic and societal development in any country. This exemplifies the importance of engineering in causing a change in any society. From the conduct of activities globally, the massive infrastructures, the drive to have better approaches to issues, the need to meet up with the current realities all attest to the importance of engineering. This is in line with the findings of the Royal Academy of Engineering (RAE) which argued that engineering capacity is of significance to the economic and social development of a nation (Matthews, Ryan-Collins, Wells, Sillem and Wright, 2012). With engineering having an influence in all processes, a proper adherence to it can help in improving production in all climes which will contribute to economic and social development. With Africa taking a backseat in all indices of development, it is needful that effort be made to improve the conduct of engineering education in Africa. This can be done by encouraging technology transfer from developed countries having in mind the need to consider the local culture resident in the region.

Winberg, Jacobs, Garraway, and Engel-Hills (2016) were of the opinion that the body of literature in engineering programs seems difficult for students and their teachers and these engineering programs are constrained by high attrition rates, poor performance in students and lack of diversity which begs the need for an overhaul in the program. Though lots of effort and commitment has been made by the government to change this by investing in engineering education to improve the quantity, quality and diversity of engineering graduates the body of knowledge seem difficult to students and their teachers. This is in line with findings of other studies which saw engineering programs as difficult as reported in the works of Stiwne and Jungert (2010) and king (2012) but no reason was given to understand what makes engineering program challenging despite the long span of its existence. Also, engineering education by reason of its difficulty has always been embraced by males to the detriment of the females. This has not encouraged inclusion in engineering education in Africa.

Matthews et al (2012) supporting this report on the findings of a study on engineering education in sub-Saharan Africa and contorted that engineering is pivotal in contributing to the economic and social development of any country. According to them, there was a severe and chronic undersupply of engineers in the country which was attributed to the small turnout of students from the university to meet the demands in most Sub Saharan African countries. Though South Africa amongst other Sub Saharan African countries has high-quality engineering resources, there is still an undersupply of engineering capacity in South Africa. Another reason that was attributed to the low supply of engineering capacity is the emigration of competent hands to other countries and the rate of emigration was revealed to match the number of graduates produced each year (Lawless, 2005). The search for greener pastures and better life has necessitated the massive emigration of competent hands from South Africa to other countries at the detriment of the south African landscape in general and the engineering sector in particular not forgetting education. This results in loss of capable hands that can contribute to the practice of engineering education in South Africa. They further stated that $40 \%$ of professional engineers in Sub Saharan Africa were of the opinion that engineering education cannot deliver the necessary skills that are relevant to the graduate. One of the challenges of engineering education, as opined by Shay (2016), is the lack of responsiveness and relevance in the undergraduate curriculum. This is supported by Fomunyam (2017) who posit that curriculum is the bedrock of all learning experiences and must be geared towards creating the necessary skills for producing graduates that will be relevant to the societal needs. In the curriculum, relevance is vital as what obtained in the past might not be obtainable now. So, the curriculum must be flexible and adaptable to current realities. This is further supported by Shay (2016) who opined that the curriculum must be relevant to the current situation and must be appropriate for meeting the learning needs of students. The society and the job market have changed and there is a need for the graduates to have the skills that fit into this changing role which an inadequate curriculum cannot provide. This typifies the need to encourage flexibility and adaptability of the curriculum to the current situation. Shay (2016) further argues that another challenge for engineering education has to do with professionalism. The necessity to tailor the practice of engineering to suit local needs above the western approach seems apt along this line. This agrees with the findings of Garuba (2015) who opined that worldviews in the global north have subjugated the higher education landscape in South Africa which does not give room for the expression of local experiences and indigenous knowledge. Also, western worldviews are upheld above indigenous experiences which do not allow the curriculum to represent the culturally accepted values, experiences, and perspectives in South Africa.

The inadequate supply of engineers can be attributed to the deficiency in the curriculum. This deficiency was attributed to poor social capital to access curriculum content vital to engineering education in the university and poor skills and qualification when exiting the university (Fomunyam, 2017). Under such circumstances, students are unable to make meaning of the content delivered to them or fail to develop the required skills pertinent for them to acquire before leaving the university. This agrees with the findings of Greve (2013) who believed that a significant number of engineering students often drop out of the university within the first two years. As a result of gender and racial supremacy, the practice of engineering education has been affected in South Africa. This was revealed in the works of ECSA (2015) which revealed that out of the 16423 registered professional engineers in the country, 70 percent of them were white and out of the 16423 registered professional engineers, 713 were females while the rest were males. These figures showed that there is a disproportionate share along race and gender lines with regards to the engineering discipline and effort must be made to ensure congruency along those lines. With whites dominating the practice of engineering education in South Africa, local and culturally relevant issues that affect most black South Africans might not be the central focus of the curriculum and this in the long run results in a disconnect between the educational institution and the society in general. 


\section{An outlook at the future of engineering education in South Africa}

With the general economic trend in Africa, environmental challenges, and the rapid development of technologies, the future of engineering education will be influenced. This paper conceptualizes the future of engineering education along technological, economic, and environmental lines. The future of engineering education in South Africa has in its various technologies that will impact disciplines and industries in the economy. Digitization brought about by engineering education will ensure that more jobs are created. Various technologies are emerging globally, and are having impact on industries and entire economies. With the acceptance of these new technologies, more jobs will be provided which can help reduce unemployment in South Africa. Engineering education in the future will lead to new jobs that were not common before and the major goal is for people to skill up to leverage on the opportunities engineering education offers in terms of technologies that drive digitization. This agrees with the findings of McKinsey Global Institute (2017) which reported that the introduction of personal computers in the 1980s led to the loss of an estimated 3.5million jobs in the United States of America but it also resulted to the creation of 19 million new jobs in the economy. This typifies that technologies will disrupt the future work mode by destroying old jobs and replacing them with new ones. It has therefore been opined that digitization has the potential to create 1.8 million new jobs as a result of improved productivity (McKinsey Global Institute, 2017).

Furthermore, the future of engineering education will have in it three emerging areas which are automation, additive manufacturing, and industrial internet. Automation which includes robotics and artificial intelligence has gained entry into the engineering profession in recent times. A report by the International Federation of Robotics revealed that an anticipated 1.4 miillion new industrial robots will be used in manufacturing globally between 2014 and 2019 and the annual production of new robots has soared from 60000 to 322000 between 2009 to 2017 (Le Roux, 2018). This was attributed to the declining cost of robots and improvement in the use of the robots themselves. Automation using robotics is more precise and efficient and it can function in extreme cases such as dull, dangerous and noxious environment and hence, its vitality in the discharge of engineering processes such as vehicle and transportation, electronic and electrical machinery (Frey et al, 2016). Automation is, therefore, an opportunity for the practice of engineering education in South Africa. Its nonadoption might become a threat if South Africa does not effectively adopt the use of these technologies in engineering education which might make the country fall behind among other countries. China is heavily investing in robotics and it was reported that the most significant market for industrial robots globally with $40 \%$ global robot purchase is China. This, in the long run, might be a threat to low-cost African labour (Le Roux, 2018). African engineers must seize the opportunity of producing robots in Africa which can help improve the productivity of the discipline as it has been noted that countries that manufacture and export robots have a competitive advantage in engineering (Phillips, 2018). Currently, the major producers of robots globally are Germany, Japan and the United States of America while there are no suppliers of industrial robots from Africa. South Africa is embracing the use of robotics in engineering especially in the automotive industries (Hendrikse, 2014) but there is a need to champion more initiatives that will ensure greater use of robots in the practice of engineering education

Magwentshu, Rajagopaul, Chui and Singh (2019) argued that South Africa had 2\% average Gross Domestic Product (GDP) growth rate between 2006-2018 which represented a $43 \%$ decline in the previous decade and unemployment increased to $29 \%$ in 2019 which was the highest in a decade. These statistics are staggering, and it shows a decline along the economic lines in South Africa and this will be consequential on the practice of engineering education. With this challenging situation, there is a need to ensure that the economy is revived, and engineering education is pivotal to the revival of the economy. It was further opined that with the emerging technologies in engineering, digitization could be a veritable boost to this economic situation which has various advantages. With digitilization, there would be the provision of new jobs especially for women and this will contribute to female empowerment and there will be more demands for technologically enabled jobs which can help in employing 1.7million graduates. By leveraging on technologies that engineering education will provide to improve productivity and innovation, South Africa can become a productive and highly competitive industry (McKinsey Global Institute, 2017).

With the fourth industrial revolution, the practice of engineering education will be influenced by the technologies that come with it. One notable area along this line is the use of unmanned aerial vehicles otherwise referred to as drones which can explore long distances and extreme landscapes, break the difficulties associated with movement in regions of conflict. The use of drones in engineering education can help in surveillance construction site monitoring, remote evaluation and supervision which will make the discipline better. According to McKinsey Global Institute (2017), technologies embedded in engineering education will influence the nature of work in South Africa which can help in contributing and boosting the economy. In the future, there will be a disruption in the production process which will have in it various technologies such as robot-assisted production which has the propensity to sufficiently increase precision and efficiency and also reduce the mishaps that might come from human errors. Leveraging these technologies will help to ensure greater productivity in many disciplines in South Africa. As a result of productivity that comes with these technologies, and improvement in the conduct of business, it will also contribute to the entire South African economy. The opportunities that these technologies will provide has influence in many disciplines and in mining, which is one of the historic anchors of South Africa`s economy, it contributes more than R300 billion to the GDP and employs more than 450000 people which makes it the major economic strength of various communities (McKinsey \& Company, 2019). It was revealed that the productivity of the mining sector in South Africa has declined over the years and when compared to mining in other regions. It has been noted that automation can help in providing 
real gain with the span of a few years if technologies are embedded in the production mix. Engineering education with its various emerging technologies will also impact on the retail and banking sector in the future by significantly improving productivity. This will be achieved by improving customer experience, reducing operational cost and boosting the share of the customer's wallet.

As a result of improvement in engineering education in the future, humans and robots will have a complementary relationship that can help in improving productivity. With engineering being a field that comes with lots of rigors, incorporating robots will help people in doing routine, rigorous, dangerous and repetitive work which will enable them to focus more on other higher pursuits such as leadership, decision making, and critical thinking. The pace at which engineering education is progressing is quite remarkable and it can change work processes, communication approaches, and overall productivity. With digitization being a component of engineering education, it could result in a breakthrough in women's empowerment. This implies that as a result of digitization, new jobs will be created for women and this can ensure that there is an increase in the percentage of women in South Africa's workforce to $45 \%$ by 2030 and create 1.6 million new jobs for women (McKinsey \& Company, 2019). Some works that are considered dangerous for the female as a result of gender consideration in the factories, industries, and mining will be done alongside robots which will only require more expertise and leadership. With the clamour for the inclusion of women and women empowerment, digitization will influence the future of work. The onus is on women to build themselves with new skills and education and be able to navigate different jobs easily leveraging on the various technologies that will come in the future brought about by engineering education. As a result of long-established social and cultural dictates which has encouraged patriarchy that seem to encourage male domination in notable issues of discourse, there is a need to have an overhaul which technologies can provide. The forces of engineering education manifested in technology and innovation that come with this age can ensure that gender equality is encouraged in the workplace and this, in the long run, might encourage sustainability.

The future of engineering education in South Africa will also be influenced by additive manufacturing. Additive manufacturing ( $3 \mathrm{D}$ printing) is applicable by using laser printers to produce objects by printing tiny layers of materials on each other. There has been an improvement in additive manufacturing as a result of innovation in material science and computer-aided designs (CAD). With 3D printing, vital tools that are needed for the practice of engineering education can be produced and those needed in Jet engines and medical equipment (Rotman, 2013). This offers immense benefit for the practice of engineering education practitioners and creates new business models which sever the gap between inventors and the market. With 3D printing, there will be additive manufacturing of tools necessary for engineering processes in South Africa. With the mobility of 3D printers, it has the ability to be used at any clime compared to heavy engineering machinery and it now has reducing price, consumes less energy than traditional machinery and in engineering education, spare parts can be easily printed and this reduces the toll on movement, transportation and other logistics (Juma, 2015)

Lastly, the internet of things (industrial internet) will also in the future influence the practice of engineering education. The internet of things can be defined as the application of information and communication technologies to connect people to variety of things which can include computers, smartphones, vehicles, household equipment, etc. Examples of this include autonomous vehicles, connected light bulbs, smart houses, smart cars, smart refrigerator, Wi-Fi connected teapots. A research by Accenture (2015) revealed that by the year 2020, there will be 50 billion things connected to the internet. With the internet of things allowing people to remotely connect to things, it can influence the practice of engineering education by enabling the connection between machines and machinery in engineering through the use of information communication technologies otherwise referred to as cyber-physical production systems (CPPS). Hence, engineering education in the future will have various machines connected to each other and information will be relayed through the entire manufacturing chain such as from engines to coolers, conveyor belts, haulage and logistics, transportation, quality control, geographic information systems, etc. the internet of things also leverages on big data which can be used in forecasting and prediction which will improve the function of tools and equipment (Accenture, 2015) along engineering lines. internet of things is vital in engineering education especially in machinery and materials, electrical and electronic equipment, transportation, energy, construction. With much efficiency in this engineering branches, it was projected that there will be a significant improvement in these sectors which can amount to 15 trillion dollars by 2030 (Accenture, 2015).

The internet of things has not received the wide appeal in Africa and it's at its infant stage. But it has a vital prospect of contributing to engineering education in Africa. This is in line with the findings of Accenture (2015) which noted that smart technologies using the internet of things can help in lowering maintenance, service and repair costs, improves the use and efficiency of energy and reduce the predisposition to risk hence improving regulatory compliance. The internet of things offers unique opportunities for the practice of engineering education in South Africa if it is leveraged on.

Data is becoming a major resource of the future, there is a need to tap into the immense opportunity it offers for socioeconomic development in South Africa. Finally, the future of engineering education will be shaped by the availability of affordable energy/electricity as well as fast, reliable and open internet. It is therefore imperative that connectivity is improved in Africa to drive the necessary facilities needed in the future to influence the practice of engineering education.

\section{Conclusion and recommendation}

This paper has looked at the future of engineering education in South Africa and various evidences have been used to predict what the future of engineering education will look like. It is important to bear in mind that the world is moving towards a knowledge-based economy which will be powered by series of 
technological development and these technologies possess immense potential to contribute to development in South Africa. With the possibility of the nature of work in engineering education to be changed in the future, there is a need for the government to invest heavily in building the knowledge economy. This will avail the people of South Africa the opportunity to benefit from various emerging technologies and still maintain their relevance by filling up the gaps in their skills and education. With various issues of westernization, professionalism and inadequacy associated with the curriculum in South Africa, government must endeavour to ensure that the educational curriculum aligns with the societal need. This will ensure that there is synergy between the educational institutions and the society at large. There is a need to focus on technical and vocational skills more in this era as it has the tendency to contribute to engineering education in South Africa. To ensure that engineering education braces up with the changes enunciated in this study, government should intensify efforts on STEM education which has the ability to contribute to engineering education in South Africa. This will equip new entrants into the labour market with relevant future skills such as needed in automation and robotics, data analytics. With the future of work in engineering education being taken over by automation, there is a need to incorporate into the curriculum leadership and management courses, critical thinking, change management, communication, crisis management.

\section{References}

Accenture (2015). Industrial Internet Insights Report 2015. Accessed on 19 November 2019 from https://www.accenture.com/t20150523T023646__w_ _/us-en/_acnmedia/Accenture/ConversionAssets/DotCom/Documents/Global/PDF/Dualpub_1 1/Accenture-Industrial-Internet-Insights-Report2015.pdf

ECSA. (2016). Engineering Council of South Africa Annual Report. Johannesburg: Engineering Council of South Africa. Engineering Education, Pretoria.

Fomunyam, K. G. (2017). Decolonising the Engineering curriculum in a South African University of Technology. International Journal of Applied Engineering Research, 12(17),6797-6805.

Frey, C., Osborne, M., and Holmes, C., editors (2016). Technology at Work v2.0: The Future is Not What it Used to Be. Citi GPS: Global Perspectives and Solutions. University of Oxford

Garuba, H. (2015). What is an African curriculum? Mail \& Guardian. Retrieved from

Greve, N. (2013). $43 \%$ of engineers say SA engineering degrees inadequate. Engineering News Retrieved from http://www.engineeringnews.co.za/article/43of-engineers-say-sa-engineering-degrees-inadequate2013-06-25

Juma, C. (2015). The 3D Printing Revolution. New African, 6 March.
King, C. J. (2012). Restructuring engineering education: Why, how and when? Journal ofEngineering Education, 101(1), 1-5.

Le Roux, D. B. (2018). Automation and employment: The case of South Africa. African Journal of Science, Technology, Innovation and Development, 10(4), 507-517.

Martin, P. (2018). Why go to university? The past and future of engineering education. In The Interdisciplinary Future of Engineering Education (pp. 17-27). London: Routledge.

Matthews, P., Ryan-Collins, L., Wells, J., Sillem, H. and Wright, H. (2012). Engineers for Africa: Identifying engineering capacity needs in sub-Saharan Africa. Royal Academy of Engineering, Africa-UK Engineering for Development Partnership.

McKinsey \& Company. (2019). Putting the shine back into South African mining: A path to competitiveness and growth. Johannesburg: Mckinsey \& Company.

McKinsey Global Institute. (2017). Jobs lost, jobs gained: Workforce transitions in a time of automation. Johannesburg: Mckinsey \& Company.

Magwentshu, N., Rajagopaul, A., Chui, M. and Singh, A. (2019). The future of work in South Africa Digitization, productivity and job creation. Johannesburg: Mckinsey \& Company.

Phillips, R. (2018). Automation will create more jobs. HR Future, 2018(Apr 2018), 8-9.

Rotman, D. (2013). The Difference between Makers and Manufacturers. MIT Technology

Shay, S. (2016). Decolonising the curriculum: it's time for a strategy. The Conversation. https://theconversation.com/decolonising-thecurriculum-its-time-for-a-strategy-60598

Stiwne, E. E., \&Jungert, T. (2010). Engineering students" experiences of transition from study to work. Journal of Education and Work, 23(5), 417-437.

Winberg, C., Winberg, S., Jacobs, C., Garraway, J., \& EngelHills, P. (2016). „I take engineering with me': epistemological transitions across an engineering curriculum. Teaching in Higher Education, 21(4), 398-414.

Winberg, C., Winberg, S., Jacobs, C., Garraway, J., \& EngelHills, P. (2016). „I take engineering with me': epistemological transitions across an engineering curriculum. Teaching in Higher Education, 21(4), 398-414. 